\title{
Dural sinus malformation in the early childhood: case report
}

\author{
João Paulo Mattos ${ }^{1}$, João Paulo C. de Almeida ${ }^{2}$, Lucas Alverne F. Albuquerque ${ }^{3}$, \\ Marcelo Otoch ${ }^{4}$, Ricardo Leite de Aquino ${ }^{4}$, Jubya L. R. Bastos ${ }^{5}$ \\ Albert Sabin Hospital, Fortaleza, CE, Brazil.
}

\section{ABSTRACT}

Background: Arteriovenous malformations (AVM) are rare disease in pediatric age group and dural sinus malformation (DSM) has even a lower incidence rate. DSMs are associated with a mild male dominance and onset symptoms appear around 5 months of age. The most common clinical presentation is macrocrania, seizures, psychomotor delay, intracranial hemorrhage, congestive heart failure and brain ischemia. Early recognition of these lesions is essential to prevent brain injury for ischemia and intracranial hypertension. Case description: We discuss the case of a 4 month-old boy presenting with macrocrania and signs of intracranial hypertension secondary to a transverse sinus dural arteriovenous malformation. This case was successfully treated by endovascular procedure reaching the goal of the treatment that is to obliterate the arterial portion of the fistula while preserving cerebral venous drainage to reduce the pial reflux in order to prevent venous hypertension and ischemic complications.

\section{KEYWORDS}

Dural sinus malformation in children. Dural arteriovenous shunt in children.

\section{RESUMO}

Malformação de seio dural na infância: relato de caso

Contexto: As malformações arteriovenosas (MAVs) são raras na faixa etária pediátrica, e as malformações de seio dural (MSD) possuem uma taxa de incidência ainda menor. As MSDs estão associadas a uma pequena predominância no sexo masculino e os sintomas aparecem por volta dos 5 meses de idade. As apresentações clínicas mais comuns são: macrocrania, crises convulsivas, atraso no desenvolvimento neuropsicomotor, hemorragia intracraniana, insuficiência cardíaca congestiva e isquemia cerebral. O reconhecimento precoce dessas lesões é essencial para prevenir o dano cerebral por isquemia e hipertensão intracraniana. Relato do caso: Discutimos o caso de um garoto de 4 meses de idade apresentando macrocrania e sinais de hipertensão intracraniana secundários a uma malformação arteriovenosa de seio dural transverso. Este caso foi tratado com sucesso por procedimento endovascular, alcançando o objetivo do tratamento, que é ocluir a porção arterial da fístula e preservar a drenagem venosa cerebral, para reduzir o refluxo pial e assim prevenir a hipertensão venosa e possíveis complicações isquêmicas.

\section{PALAVRAS-CHAVE}

Malformação de seio dural em criança. Fístula arteriovenosa dural em criança.

\section{Introduction}

Arteriovenous malformations (AVM) has a low incidence with an annual case detection rate estimated as $0.9-1.5$ per 100,000 population. ${ }^{1}$ Dural sinus malformation (DSM) has even a lower incidence, representing $4.8 \%$ to $10 \%$ of the AVM in the pediatric age group. ${ }^{2,3}$

We discuss the case of a 4-month-old boy presenting a transverse sinus dural AVM successfully treated by endovascular procedure.

\section{Case description}

A 4 month-old boy was admitted at the emergency room after three days with vomiting and irritability. At the neurological examination, the child had a protrusion of the occipital bone at the posterior fossa and distended and enlarged anterior fontanel.

A magnetic resonance imaging (MRI) (Figure 1) showed the presence of an important obstructive hydrocephalus associated with a large and round heterogeneous

1 Neurosurgeon at Albert Sabin Hospital, Fortaleza, CE, Brazil.

2 Neurosurgery resident at Universidade de Campinas (Unicamp), SP, Brazil.

3 MD Neurosurgery resident at Santa Casa de Belo Horizonte, MG, Brazil.

4 Intenventional radiologist at General Hospital of Fortaleza, Fortaleza, CE, Brazil

5 Pediatrician at Albert Sabin Hospital, Fortaleza, CE, Brazil. 
A

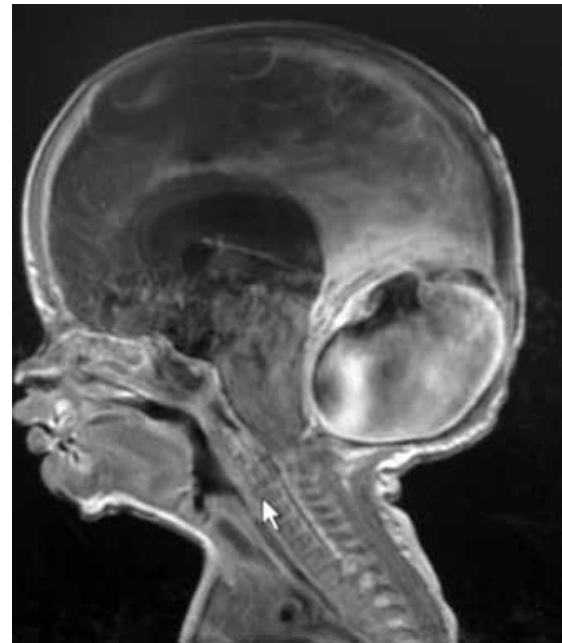

B

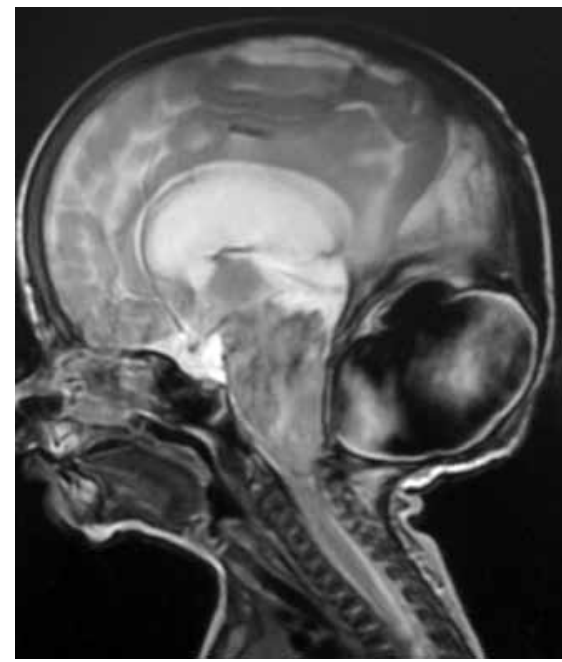

C

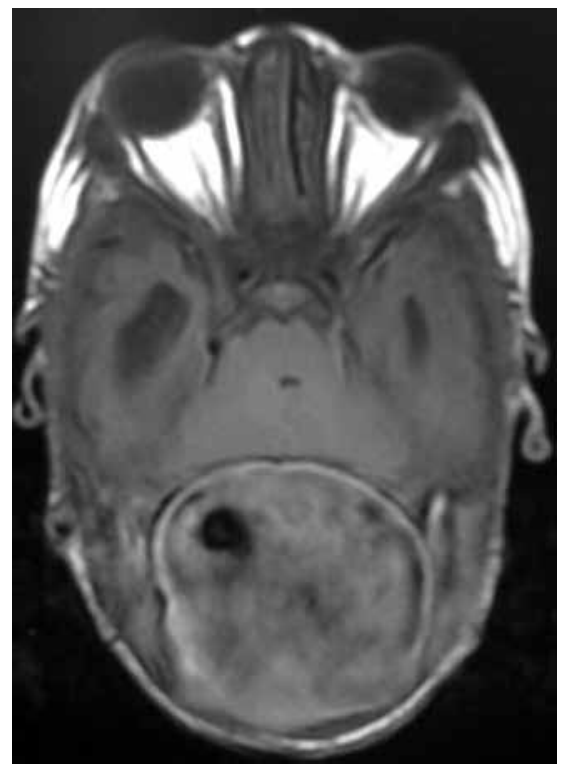

Figure 1-MRI A) Sagital T1WI; B) Sagital T2WI; C) Axial T1WI show the presence of an important obstructive hydrocephalus associated with a large and round heterogeneous but predominantly high dense posterior fossa lesion with important compression of the cerebellum. but predominantly high dense posterior fossa lesion with important compression of the cerebellum. The patient was then submitted to the ventriculoperitoneal shunt (VP shunt) in order to manage the raised intracranial pressure due to hydrocephalus. Following the shunt the patient showed complete resolution of the irritability and vomiting with depression of anterior fontanel.

Post-operative MRI and magnetic resonance angiography (MRA) demonstrated the presence of a bilateral subdural higroma associated with a contrast enhancing large extra-dural lesion occupying the entire occipital aspect of the posterior fossa with a central hipointense signal suggestive of flow void, which was diagnosed as a vascular abnormality.

The patient was referred to a digital angiography which showed dural direct arteriovenous fistula fed by a single enlarged left occipital artery and drained to the transverse sinus leading to an important enlargement of the bilateral transverse sinus including the torcula, with no signs of jugular bulb stenosis, pial reflux, or cavernous sinus abnormality (Figure 2A). An endovascular closure after a single session was chosen for management of the lesion where an intra-arterial catheterization was done with complete occlusion of the left occipital artery at the union of the artery and transverse sinus. The navigation was performed using a flow dependent catheter with a 0.10 microguide wire. The material used to treat the fistula was Hystoacril mixed with lipiodol (1:4). The immediate post-embolization angiography showed complete resolution of the fistula (Figure 2B).

The patient presented a very good evolution and in a follow up at age of 8 months presented no deficits or developmental delay; at this time the VP shunt was changed due to its dysfunction. There was no subdural higroma after the change of the VP shunt. The posterior fossa lesion showed a hypodense aspect with important decrease in size at the computed tomography scan without contrast administration.

\section{Discussion}

DSM is the consequence of nonmaturation of a sinus segment and it leads to secondary arteriovenous shunt in the affected segment of the sinus. So DSM with their mural arteriovenous shunt (AVS) are different from neonatal and infant AVS, since shunts in DSMs seem to be a secondary phenomena at the level of the sinus, usually with low flow characteristics. ${ }^{2}$

In a recent series of DSM with giant lakes published by Barbosa et al., ${ }^{2}$ studying AVM in the pediatric age group, vein of Galen malformation (VGAM) is the main 
pathology, representing $51.1 \%$. Dural arteriovenous shunts (DAVS) represented $8.3 \%$ of all AVM in children. ${ }^{2}$

Within the pediatric DAVS, three types of lesions can be individualized: 1) DSM; 2) infantile type of DAVS and 3) adult type of DAVS.

DSM is a type of lesion in which the arteriovenous shunts are usually secondary and accessory to the sinus malformation. Infantile type of DAVS are often multifocal, with no sinus malformation, however present

A

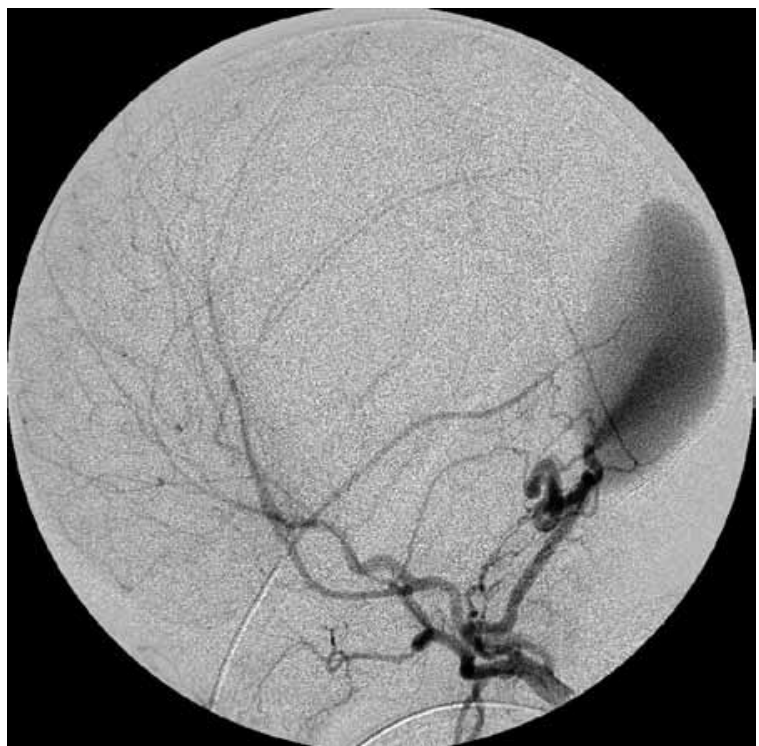

B

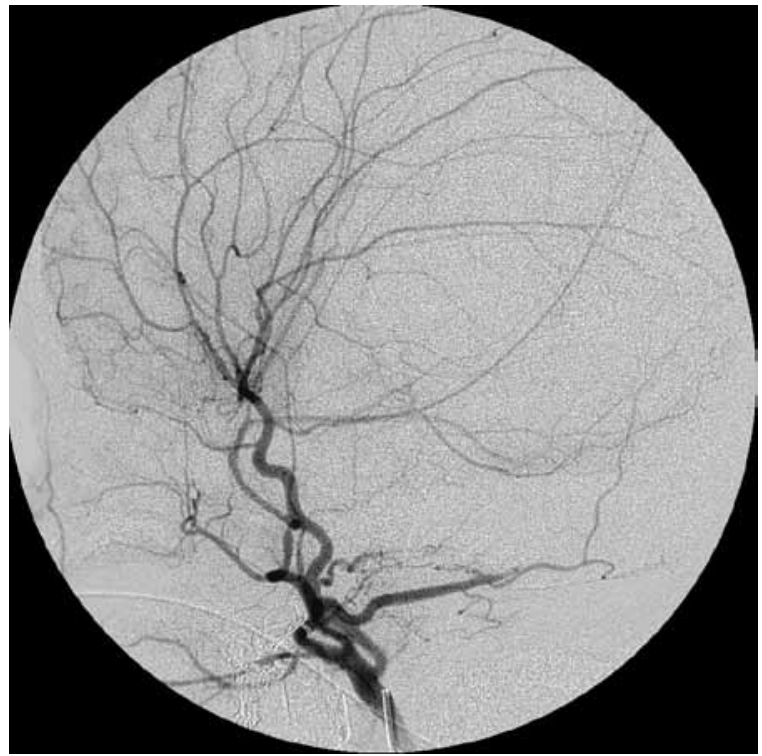

Figure 2 - Digital angiography. A) Pre-embolization angiography - dural direct arteriovenous fistula fed by a single enlarged left occipital artery and drained to the transverse sinus was found leading to an important enlargement of the bilateral transverse sinus including the torcula, with no signs of jugular bulb estenosis, pial reflux, or cavernous sinus abnormality. B) Post-embolization angiography showed complete resolution of the fistula. with large sinus and, sometimes, secondary jugular occlusion. In the adult form of DAVS, the venous sinus are usually small and sometimes partially thrombosed and can be secondary to an another local event. ${ }^{7}$

DSM with giant lakes involving the torcular and/ or adjacent sinuses represent $57.7 \%$ of all DAVS in children. ${ }^{2}$ Therefore, DSM with giant lakes represents $4.8 \%$ of all $\mathrm{AVM}^{2}$

DSM are associated with a male dominance (1.9:1), and signs and symptoms of the DSM usually appear around 5 months of age, although some lesions are identified in the antenatal period. Some of the most common clinical presentation are macrocrania, seizures, psychomotor development delay, intracranial hemorrhage, congestive heart failure and brain damage. ${ }^{2,5-7}$

Although the high rate of mortality, about $38 \%$ to $46 \%$, the endovascular management is the fist therapeutic choice. ${ }^{2,4,6}$ Other important factors are medical therapy with support to the treatment of cardiac failure if present and anticoagulation. ${ }^{4}$ The goal of the treatment is to obliterate the arterial portion of the fistula while preserving cerebral venous drainage to reduce the pial reflux in order to prevent venous hypertension and ischemic complications. ${ }^{2,47}$ According to Barbosa et $a l .,{ }^{2} 75 \%$ of the patients who were able to be submitted to endovascular therapy presented good outcome, with only minor neurologic deficits.

The prognosis of such lesions is usually poor, with overall mortality of $38 \% .{ }^{6}$ Barbosa et al. ${ }^{2}$ highlighted some bad prognostic factors, such as: brain damage, DSM involving torcula and absence of cavernous capture; and good prognostic factors: DSM away from the torcula, presence of bilateral flow at cavernous sinuses and absence of jugular bulb dysmaturation.

\section{Conclusion}

Early recognition of these lesions is essential to prevent brain injury for ischemia and intracranial hypertension. Endovascular treatment represents the gold standard option for such lesions. Although the development of embolization techniques in the last years, new technologies and further understanding of the disease are needed in order to achieve better treatment results.

\section{References}

1. Al-Shahi R, Bhattacharya JJ, Currie DG, Papanastassiou V, Ritchie V, Roberts RC, et al. Prospective, population-based detection of intracranial vascular malformations in adults: the 
Scottish Intracranial Vascular Malformation Study (SIVMS). Stroke. 2003;34:1163-9.

2. Barbosa M, Mahadevan J, Weon YC, Yoshida $Y$, Ozanne A, Rodesch G, et al. Dural sinus malformation (DSM) with giant lakes in neonates and infants: review of 30 consecutive cases. Intervent Neuroradiol. 2003;9:407-24.

3. Garcia-Monaco R, Rodesch G, Terbrugge K, Burrows $\mathrm{P}$, Lasjaunias P. Multifocal dural arteriovenous shunts in children. Childs Nerv Syst. 1991;7:425-31.

4. Haana TR, Padberga RD, Hagebeukc EE, Aronica E, Van Rijn RR, Majoie CB, et al. A case of neonatal dural sinus malformation: clinical symptoms, imaging and neuropathological investigations. Europ J Paed Neurol. 2008;12:41-5.

5. Kincaid PK, Duckwiler GR, Gobin YP, Viñuela F. Dural arteriovenous fistula in children: endovascular treatment and outcomes in seven cases. AJNR. 2001;22:1217-25.
6. Morita A, Meyer FB, Nichols DA, Patterson MC. Childhood dural arteriovenous fistulae of the posterior dural sinuses: three case reports and literature review. Neurosurgery. 1995;37:1193-9.

7. Ozanne A, Alvarez $\mathrm{H}$, Krings $\mathrm{T}$, Lasjaunias P. Pediatric neurovascular malformations: vein of Galen arteriovenous malformations (VGAM), pial arteriovenous malformations (pial AVM), dural sinus malformations (DSM). J Neuroradiol. 2007;34:145-66.

This article does not have any support in the form of grants.

Endereço para correspondência

Lucas Alverne Freitas de Albuquerque

Rua dos Aimorés, 1006, ap. 202

30140-071 - Belo Horizonte, MG, Brazil

E-mail: lucasalverne@yahoo.com.br 